\title{
The analysis of urban travellers' latent preferences to explain their mode choice behaviour
}

\author{
M. Migliore, M. Catalano, A. Lo Burgio \& L. Maritano \\ Department of Energy, Transport Research Group, \\ University of Palermo, Italy
}

\begin{abstract}
Our research aims to explore the impact of latent variables, mirroring urban travellers' attitudes and perceptions, on the individual decision making process regarding the mode of transport. The paper describes the first results of an ongoing research activity, which derive from a pilot study conducted in Palermo, the capital of the Sicilian Region (in the south of Italy), and demonstrate that policy makers, in designing a socially desirable and environmentally sustainable urban mobility system, should take into account how travellers perceive the qualitative dimensions of transport.

Keywords: mode choice behaviour, discrete choice-latent variable model, attitudes and perceptions, public transport, infomobility services.
\end{abstract}

\section{Introduction}

In designing a desirable and sustainable urban mobility system, transportation planners have to increase their understanding of the hierarchy of preferences that drives individual choices of transport mode.

In the relevant empirical literature, most models use service attributes to explain mode choice behaviour. Decision maker-specific variables are also often included to allow for individual differences. This research aims to examine whether the construction of latent variables, mirroring travellers' attitudes and perceptions, is able to provide insights into the mode choice analysis. In particular, we intend to investigate the explanatory role played by users' latent preferences for reliability, flexibility, convenience, comfort, safety along with 
the effects of symbolic-affective motives (e.g.: for me the car is part of my identity, a way to distinguish myself from others).

To achieve these objectives, a pilot study was carried out in Palermo, the capital of the Sicilian Region (in the south of Italy), where, currently, the national government and the local authorities are investing significantly to improve the "weak" public transport system. We administered to an initial sample of 125 travellers a questionnaire containing four parts: a section to obtain psychometric data on individuals' attitudes and perceptions toward different qualitative dimensions of transport; an SP survey part providing hypothetical scenarios to choose among private car, bus and train, based on bilevel variables like cost $(€)$ and different travel time (minutes) components (walking, waiting, in-vehicle, parking.); a section on the socioeconomic characteristics of the respondents and another on their current travel behaviour (also focusing on trip chains).

In more detail, under the first section of the questionnaire, the survey participants were asked to what extent they agreed with several statements on attitudes and perceptions toward car and public transport as travel alternatives for journey-to-work (study) trips; to rate the statements, the respondents were required to use a five level semantic scale ranging from "most disagree" to "most agree".

In developing the SP experiment, to simplify the choice task, we combined the fractional factorial design technique with the block design approach, thus obtaining eight choice games for each decision-maker.

\section{Specification and estimation of choice models to analyse the mode choice behaviour in Palermo}

Based on the explanatory variables illustrated in the previous section, we simulated mode choice behaviour referring to random utility theory; in particular, the empirical analysis was performed through the logit framework (Ben Akiva et al. [1]). Furthermore, to enhance the explanatory power of the resulting mode choice model, we integrated the base specification, in one case, with socioeconomic characteristics of the respondents, in the other case, with indicators of their psychological traits deriving from the responses to survey questions on individual attitudes and perceptions. In the end, to capture the correlation between bus and train (these modes being two alternative forms of public transport), a nested logit model was estimated.

One thousand SP choice observations were processed for model estimations, which were executed by the BIOGEME 1.8 econometric software (Bierlaire [2]).

\subsection{Specification}

Firstly, we developed a logit model (see table 1), to simulate the choice among car, bus and train, with the systematic part of utility functions involving walking time (min.), waiting time (min.), in-vehicle time (min.), parking time (min.) and cost $(€)$. To improve the choice model, socioeconomic attributes, such as number 
Table 1: $\quad$ Base specification.

\begin{tabular}{c|ccccccc}
\hline $\begin{array}{c}\text { Coeff. } \\
\text { Alt. }\end{array}$ & $A S C_{\text {Bus }}$ & $A S C_{\text {Train }}$ & $\beta_{\text {T-Walk }}$ & $\beta_{\text {T-Wait }}$ & $\beta_{\text {T-InVehicle }}$ & $\beta_{\text {T-Park }}$ & $\beta_{C}$ \\
\hline Car & 0 & 0 & $\begin{array}{c}T \text {-Walk } \\
\text { (min.) }\end{array}$ & 0 & $\begin{array}{c}\text { T-InVehicle } \\
\text { (min.) }\end{array}$ & $\begin{array}{c}\text { T-Park } \\
\text { (min.) }\end{array}$ & $\begin{array}{c}\text { Cost } \\
(€)\end{array}$ \\
Bus & 1 & 0 & $\begin{array}{c}\text { T-Walk } \\
\text { (min.) }\end{array}$ & $\begin{array}{c}\text { T-Wait } \\
\text { (min.) }\end{array}$ & $\begin{array}{c}\text { T-InVehicle } \\
\text { (min.) }\end{array}$ & 0 & $\begin{array}{c}\text { Cost } \\
(€)\end{array}$ \\
Train & 0 & 1 & $\begin{array}{c}\text { T-Walk } \\
\text { (min.) }\end{array}$ & $\begin{array}{c}\text { T-Wait } \\
\text { (min.) }\end{array}$ & $\begin{array}{c}\text { T-InVehicle } \\
\text { (min.) }\end{array}$ & 0 & $\begin{array}{c}\text { Cost } \\
(€)\end{array}$ \\
\hline
\end{tabular}

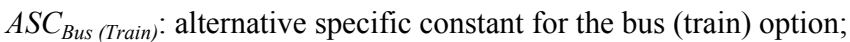

T-Walk: walking time attribute;

T-Wait: waiting time attribute;

T-InVehicle: in-vehicle time attribute;

T-Park: parking time attribute;

Cost: transport cost variable.

Table 2: $\quad$ Socioeconomic variables integrated into the base specification.

\begin{tabular}{c|cccccccc}
\hline Coeff. & $\beta_{\text {NCars }}^{\text {Bus }}$ & $\beta_{\text {NCars }}^{\text {Train }}$ & $\beta_{\text {Male }}^{\text {Bus }}$ & $\beta_{\text {Male }}^{\text {Train }}$ & $\beta_{\text {Job }}^{\text {Bus }}$ & $\beta_{\text {Job }}^{\text {Train }}$ & $\beta_{\text {Student }}^{\text {Bus }}$ & $\beta_{\text {Student }}^{\text {Train }}$ \\
\hline Car & 0 & 0 & 0 & 0 & 0 & 0 & 0 & 0 \\
Bus & NCars & 0 & Male & 0 & Job & 0 & Student & 0 \\
Train & 0 & NCars & 0 & Male & 0 & Job & 0 & Student \\
\hline
\end{tabular}

NCars: number of available cars per driving-license holder within the household;

Male: 1 if the respondent is a man, 0 otherwise;

$J o b: 1$ if the respondent is an entrepreneur or a manager or a professional, 0 otherwise;

Student: 1 if the respondent is a student, 0 otherwise.

of available cars, gender and type of activity done by the respondent, were embodied into the base specification (see table 2).

Moreover, another progress was obtained by the introduction into the utility functions of psychometric indicators concerning the perceived importance of punctuality, privacy, reliability and comfort, along with symbolic-affective motivations in favour of car and the knowledge of public transport (see table 3). 


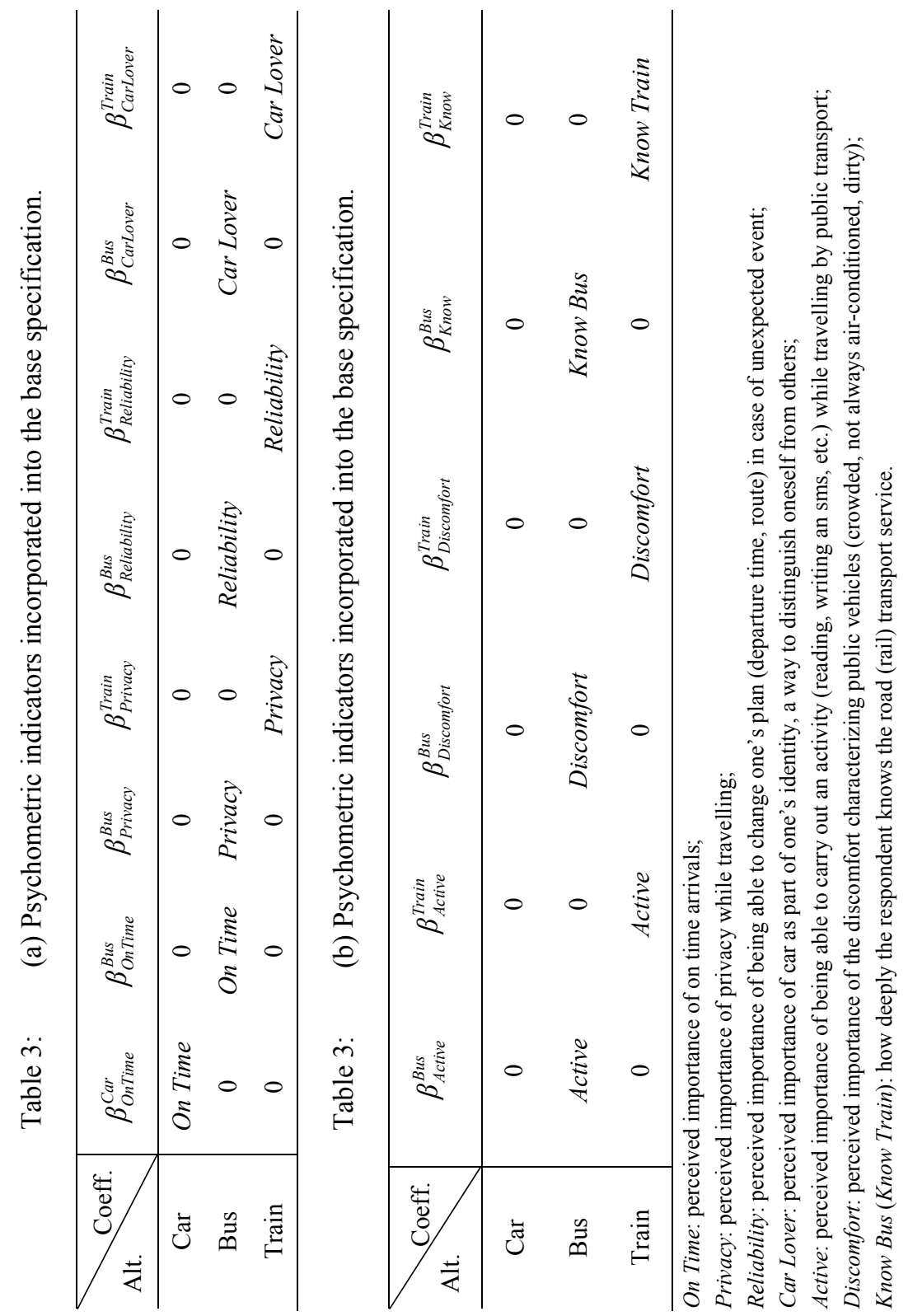




\subsection{Estimation outcomes}

As stated above, various forms of the mode choice model were estimated: three logit models (to analyse the impact of alternatives' attributes, individual socioeconomic characteristics, decision-makers' attitudes and perceptions) and a nested logit capturing the correlation between bus and train (see figure 1).

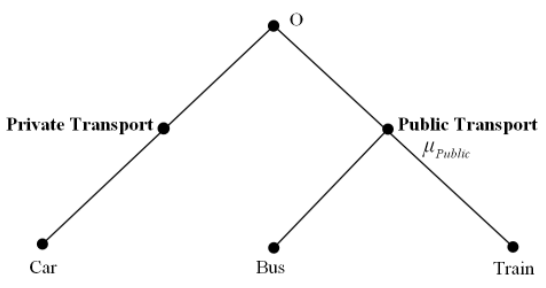

Figure 1: $\quad$ Nested logit model.

Table 4 displays the estimation outcomes. All the models are characterized by reasonable signs and, in most cases, good statistical significance of their parameters. As to the variables of the base specification, the estimation output reveals that, as expected, the walking time marginal utility is far higher (2.53 times) than the other time attributes' coefficients; more precisely, the value of walking time is about $26 € /$ hour, while the willingness-to-pay for time savings, in the other cases (waiting, in-vehicle, parking), is set at 8-10€/hour.

The model incorporating the socioeconomic variables increases remarkably the goodness of fit and points out that public transport is less appealing for males, entrepreneurs, managers, professionals and users with more available cars; on the contrary, students perceive bus and train more attractive.

The model integrating the psychometric indicators outperforms the others in terms of fit and implies the following behavioural considerations: the utility of train increases, with respect to the road-related alternatives, if the perceived importance of punctuality rises; public transport is less competitive for users who attach greater importance to privacy, public vehicles' discomfort and reliability; the same holds for decision-makers who perceive private car as a means of selfexpression; instead, individuals who appreciate the possibility of doing activities while travelling and people who have used sometimes (and therefore know) public transport services are more attracted by bus and train.

In the end, as regards the nested logit model, we found out that the scale factor determining the error term variance within the nest $\left(\mu_{\text {Public }}\right)$ is close to 1 and has a low statistical significance (t-test against 1 equal to 1 ). Furthermore, the likelihood ratio (LR) test to compare the base logit model versus the nested logit one provides a chi-square distributed LR statistic of 1.17 , which is far lower even than the critical value at the $90 \%$ confidence level for one degree of freedom (2.71); hence, the null hypothesis (the logit form holds) cannot be rejected. 
Table 4: (a) Estimated models (see $t$ ratios in brackets).

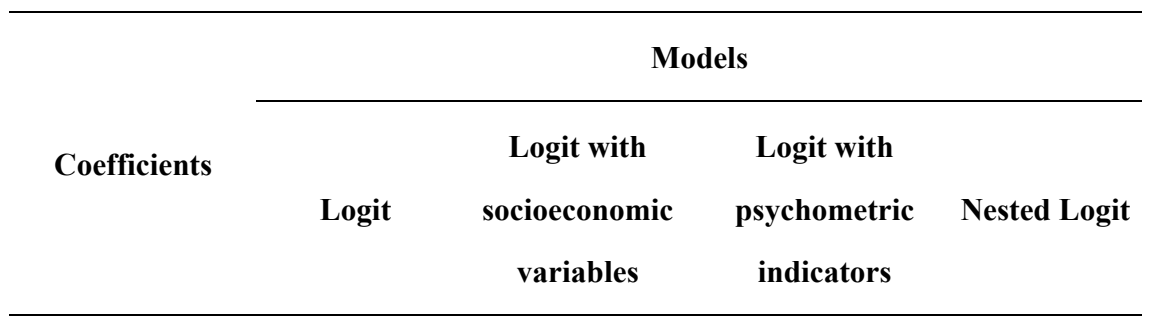

Coefficients of

$\underline{\text { modes' attributes : }}$

$\begin{array}{lcccc}\text { ASC } & -0.702 & -0.862 & -0.725 \\ A_{\text {Bus }} & -0.786 & (-1.43) & (-2.59) & (-2.37) \\ & (-2.44) & 0.507 & -0.161 & -0.151 \\ \beta_{\text {T-Walk }} & -0.125 & (1.31) & (-0.52) & (-0.52) \\ & (-0.42) & -0.158 & -0.160 & -0.142 \\ \beta_{\text {T-Wait }} & -0.152 & (-11.25) & (-11.31) & (-9.07) \\ & (-11.11) & -0.0467 & -0.0464 & -0.0413 \\ \beta_{\text {T-InVehicle }} & -0.0446 & (-2.41) & (-2.37) & (-2.34) \\ \beta_{\text {T-Park }} & (-2.33) & -0.0631 & -0.0649 & -0.0568 \\ & -0.0615 & (-8.44) & (-8.54) & (-6.91) \\ \beta_{C} & (-8.38) & -0.0475 & -0.0496 & -0.0447 \\ & -0.0453 & (-3.37) & (-3.47) & (-3.27) \\ & (-3.29) & -0.356 & -0.366 & -0.336 \\ & -0.339 & (-5.04) & (-5.12) & (-4.91)\end{array}$

Incl. value coeff. ${ }^{a}:$

$\mu_{\text {Public }}$

1.18

$(1.00)^{\mathrm{b}}$

${ }^{a}$ Inclusive value coefficient determining the error term variance within the Public nest.

${ }^{\mathrm{b}}$ t-test against 1 . 
Table 4: (b) Estimated models (see t ratios in brackets).

\begin{tabular}{|c|c|c|c|c|}
\hline \multirow[b]{2}{*}{ Coefficients } & \multicolumn{4}{|c|}{ Models } \\
\hline & Logit & $\begin{array}{c}\text { Logit with } \\
\text { socioeconomic } \\
\text { variables }\end{array}$ & $\begin{array}{c}\text { Logit with } \\
\text { psychometric } \\
\text { indicators }\end{array}$ & Nested Logit \\
\hline \multicolumn{5}{|l|}{ Coefficients of } \\
\hline variables: & & & & \\
\hline$\beta_{\text {NCars }}^{\text {Bus }}$ & - & $\begin{array}{l}-0.0966 \\
(-0.22)\end{array}$ & - & - \\
\hline$\beta_{\text {NCars }}^{\text {Train }}$ & - & $\begin{array}{l}-0.343 \\
(-1.21)\end{array}$ & - & - \\
\hline$\beta_{\text {Male }}^{\text {Bus }}$ & - & $\begin{array}{l}-0.447 \\
(-2.01)\end{array}$ & - & - \\
\hline$\beta_{\text {Male }}^{\text {Train }}$ & - & $\begin{array}{l}-0.830 \\
(-5.33)\end{array}$ & - & - \\
\hline$\beta_{J o b}^{B u s}$ & - & $\begin{array}{l}-0.397 \\
(-1.17)\end{array}$ & - & - \\
\hline$\beta_{\text {Job }}^{\text {Train }}$ & - & $\begin{array}{l}-0.542 \\
(-2.34)\end{array}$ & - & - \\
\hline$\beta_{\text {Student }}^{\text {Bus }}$ & - & $\begin{array}{l}0.454 \\
(1.83)\end{array}$ & - & - \\
\hline$\beta_{\text {Student }}^{\text {Train }}$ & - & $\begin{array}{l}0.442 \\
(2.51)\end{array}$ & - & - \\
\hline
\end{tabular}


Table 4: (c) Estimated models (see t ratios in brackets).

\begin{tabular}{|c|c|c|c|c|}
\hline \multirow[b]{2}{*}{ Coefficients } & \multicolumn{4}{|c|}{ Models } \\
\hline & Logit & $\begin{array}{c}\text { Logit with } \\
\text { socioeconomic } \\
\text { variables }\end{array}$ & $\begin{array}{c}\text { Logit with } \\
\text { psychometric } \\
\text { indicators }\end{array}$ & Nested Logit \\
\hline \multicolumn{5}{|l|}{ Coefficients of } \\
\hline $\begin{array}{l}\text { psychometric } \\
\text { indicators : }\end{array}$ & & & & \\
\hline$\beta_{\text {OnTime }}^{\text {Car }}$ & - & - & $\begin{array}{l}-0.291 \\
(-2.47)\end{array}$ & - \\
\hline$\beta_{\text {OnTime }}^{\text {Bus }}$ & - & - & $\begin{array}{l}-0.279 \\
(-1.62)\end{array}$ & - \\
\hline$\beta_{\text {Privacy }}^{\text {Bus }}$ & - & - & $\begin{array}{l}-0.0371 \\
(-0.36)\end{array}$ & - \\
\hline$\beta_{\text {Privacy }}^{\text {Train }}$ & - & - & $\begin{array}{l}-0.142 \\
(-2.01)\end{array}$ & - \\
\hline$\beta_{\text {Reliability }}^{\text {Bus }}$ & - & - & $\begin{array}{c}-0.0471 \\
(-0.32)\end{array}$ & - \\
\hline$\beta_{\text {Reliability }}^{\text {Train }}$ & - & - & $\begin{array}{l}-0.166 \\
(-1.59)\end{array}$ & - \\
\hline$\beta_{\text {CarLover }}^{\text {Bus }}$ & - & - & $\begin{array}{l}-0.375 \\
(-3.97)\end{array}$ & - \\
\hline$\beta_{\text {CarLover }}^{\text {Train }}$ & - & - & $\begin{array}{c}-0.0674 \\
(-1.07)\end{array}$ & - \\
\hline
\end{tabular}


Table 4: (d) Estimated models (see t ratios in brackets).

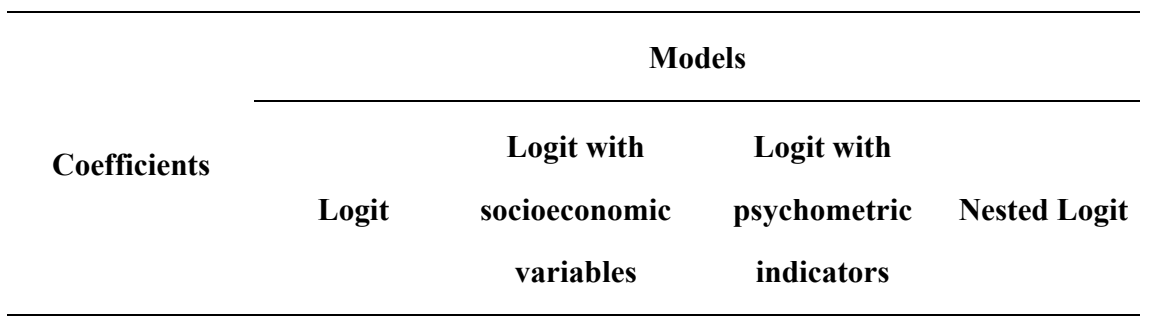

Coefficients of

psychometric

indicators :

$\begin{array}{llll}\beta_{\text {Active }}^{\text {Bus }} & - & - & 0.148 \\ & & & (1.54) \\ \beta_{\text {Active }}^{\text {Train }} & - & - & 0.114 \\ & & & (1.59)\end{array}$

$\beta_{\text {Discomfort }}^{\text {Bus }}$

$-0.200$

$(-1.90)$

$\beta_{\text {Discomfort }}^{\text {Train }}$

$-0.359$

$\beta_{\text {Know }}^{\text {Bus }}$

0.116

(1.34)

$\beta_{\text {Know }}^{\text {Train }}$

0.179

(2.87)

\begin{tabular}{ccccc}
\hline Final log likelihood & -825.412 & -799.807 & -781.150 & -824.825 \\
$\rho^{2^{*}}$ & 0.244 & 0.268 & 0.285 & 0.245 \\
Adjusted $\rho^{2^{*}}$ & 0.238 & 0.254 & 0.266 & 0.237 \\
\hline
\end{tabular}

${ }^{*}$ No coefficients. 


\section{Conclusions and future steps}

In order to highlight the importance of taking into account travellers' latent preferences, in addition to the traditional mode attributes and socioeconomic variables, when designing a more competitive public transport supply, we employed the estimated models for analysing two hypothetical scenarios.

First, we used the logit model with psychometric indicators to simulate the effect on the bus choice probability of road pricing. In more detail, we referred to a generic user who can choose between car and bus to travel $5 \mathrm{~km}$ inside Palermo and presents the following psychological traits: he does not consider auto as part of his identity, he appreciates the possibility of doing activities while travelling very much, he is remarkably impressed by the discomfort of public vehicles and, for this reason, he has rarely used the bus in the past. Figure 2 shows that charging trips towards the city centre with a $2 €$ price per trip would raise the bus choice probability by 20 percent points.

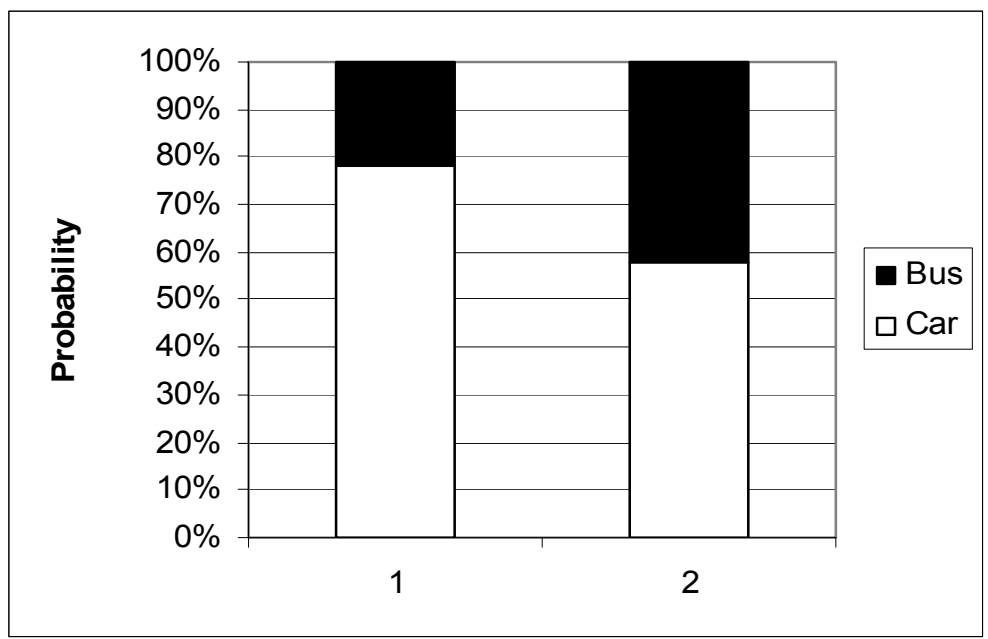

Scenario 1: no road pricing; scenario 2: road pricing

Figure 2: $\quad$ Effect of road pricing on the bus attractiveness.

Second, we investigated the effect on public transport appeal of combining road pricing with policy actions to make the bus service more comfortable and known (e.g.: lowering passenger density inside the vehicles, more vehicles with air conditioning systems, discounts on the season tickets for first time-users, ...). Figure 3 demonstrates that, if the above generic individual knows more deeply the bus service and does not perceive it as uncomfortable, a road pricing policy requiring $2 €$ to go downtown is able to produce an increase in the bus choice probability by nearly 50 percent points, well beyond the previous outcome. 


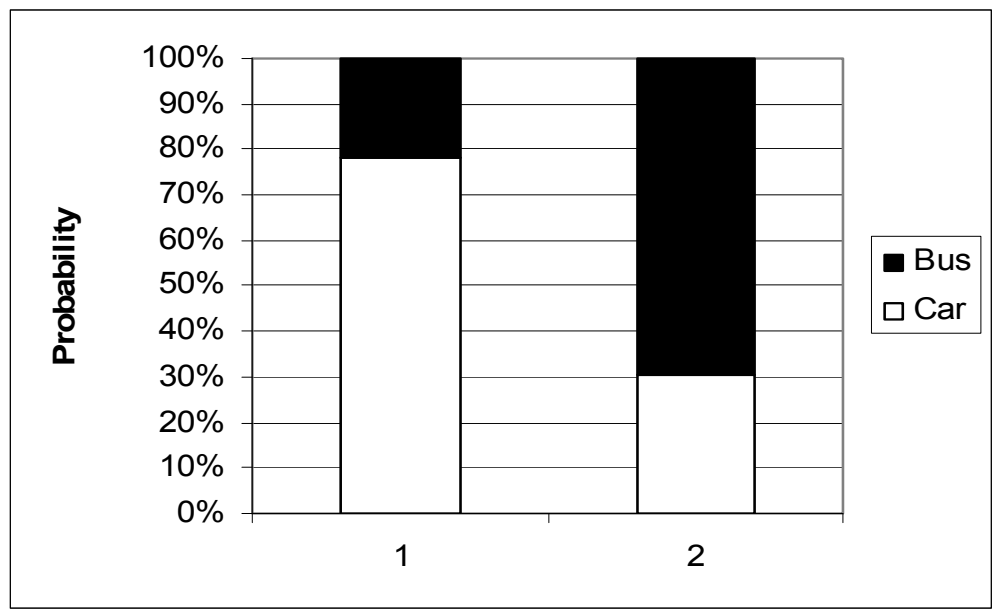

Scenario 1: no road pricing; scenario 2: road pricing

Figure 3: $\quad$ Effect of road pricing and user's attitudes and perceptions.

In conclusion, the initial results of our research support the assumption that psychological factors count in explaining mode choice behaviour and, consequently, are to be carefully analysed by transportation planners.

In the near future, we intend to repeat the survey involving a larger sample and employing a revised questionnaire to study also how the availability of infomobility services can affect the level of convenience and reliability perceived by travellers in relation to public transport. We will also perform factor analysis to extract latent variables (to be integrated into the mode choice model) from the psychometric indicators, since these cannot be introduced directly into the utility functions, because they are not causal, they are highly dependent on the phrasing of the survey question, there can be multicollinearity issues and they are not available for forecasting (Walker [3]; Walker and Ben Akiva [4]).

\section{References}

[1] Ben Akiva, M. E. and Lerman, S. R., Discrete Choice Analysis: Theory and Application to Travel Demand, The MIT Press: Cambridge, Mass, 1985.

[2] Bierlaire, M., Estimation of Discrete Choice Models with BIOGEME 1.8, http://biogeme.epfl.ch, 2009.

[3] Walker, J. L., PhD Thesis, Extended Discrete Choice Models: Integrated Framework, Flexible Error Structures, and Latent Variables, Massachusetts Institute of Technology, 2001.

[4] Walker, J. L. and Ben Akiva, M. E., Generalized random utility model. Mathematical Social Sciences, 43 (3), pp. 303-343, 2002. 